مجلة لارك للفلسفة و الذسانيات و العلوم الاجتماعية المجلد (2) العدد (41) السدنة (2021)

\title{
هيغل: من اللاهوت إلى فلسفة الدين
}

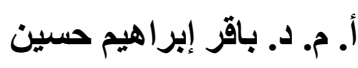

الباحث: حيدر محيسن عبود

جامعة واسط / كلية الآداب / قسم الفلسفة

haidar.123.hh.321@gmail.com

تاريخ الاستلام : 16-2021-02 ت تاربخ

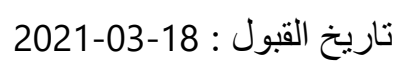

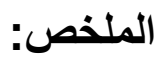

يُعتبر هيغل من الفلاسفة الذين جاءت فلسفاتهم متأخرة؛ فحياة هيغل تتقسم إلى قسمين: مرحلة الثباب، ومرحلة النضوج. أما

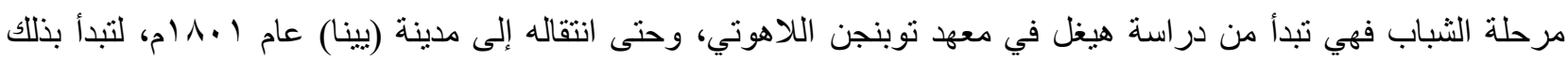

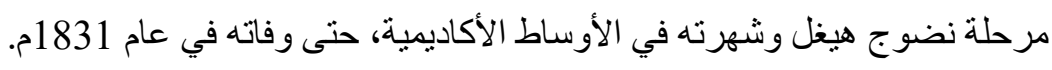

تعثبر مرحلة الثباب مرحلة مهمة في حياة هيغل، رغم أنها تمتاز بطابع لاهوتي، إلا أنها كانت منطلقًا لمشكلته الدينية

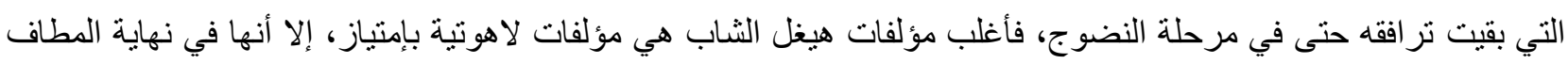

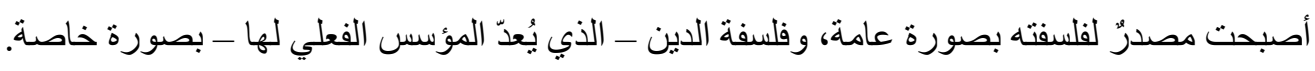

الكلمات المفتاحية:هيغل - كتابات الثباب - المسيحية - كانت - اللاهوت - الكتاب المقس - عصر التتوير - الدين الموضوعي - الدين الذاني - يسوع - اليهودية - المطلق. 


\title{
Hegel: From Theology to Philosophy of Religion
}

\section{Haidar Moheisen Abbood Assist.Prof .DR. Baqir Ibrahim Hussein \\ Wasit University / College of Arts / Department of Philosophy}

Receipt date: 2021-02-16

Date of acceptance: 2021-03-18

\begin{abstract}
Hegel is considered among the philosophers whose philosophies came late Hegel's life is divided into two parts: the stage of youth and the stage of maturity. As for the youth stage, it begins with Hegel's study at the Tubingen Theological Institute, until his move to the city of (enna) in $1801 \mathrm{AD}$, thus beginning the stage of maturity of Hegel and his fame in academic circles, until his death in 1831 AD.

The youth stage is considered an important stage in Hegel's life, although it has a theological character, but it was the starting point for his religious problem that continued to accompany him even in the stage of maturity. Religion - which is the de facto founder of it - in particular.
\end{abstract}

Key Words: Hegel, Youth Writings, Christianity, Kan, Theology, The Bible, Enlightenment, Objective Religion, Self Religion, Jesus, Judaism, the Absolute. 
في الحقيقة لا يُعتبر هيغل ناقدًا للدين المسيحي، فهو لم يرفضه رفضًا تامًا، بل أنه كان يتخذ موقفًا ازدر ائيًا من بعض التعاليم المسيحية، الأمر الذي جعله ينتقد تلك التعاليم التي لا يُحبب سماعها. وكما هو معروف أن اللاهوت الذي سمعه من اساتذته ئه

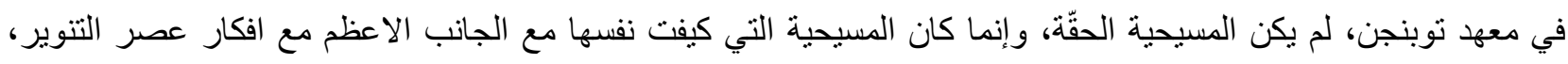
وبذلك كان اللاهوت هو تأليهًا عقلانيًا مصبوغًا، ومنقوعًا في المذهب الطبيعي الاعلى للكتاب المقد، وديانة الفهم هذه ـكما

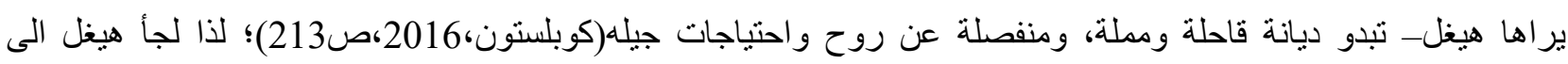
العنصر التاريخي؛ وذلك من أجل الانتصار للمسيحية، وكانت هذه الطريقة الوحيدة التي يراها ناجحة، فمن خلال رسالته التي وجهها الى زميله شلنيح، و التي يتبين فيها ان هيغل كان يطمح فيها الى هدم " الأكو اخ التي يحلو لرجال اللاهوت سُكناها، والتي

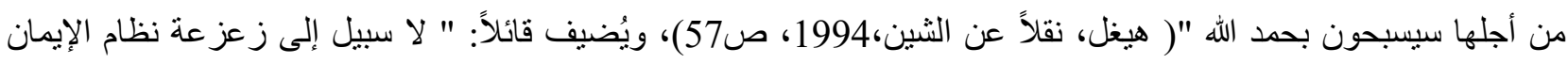

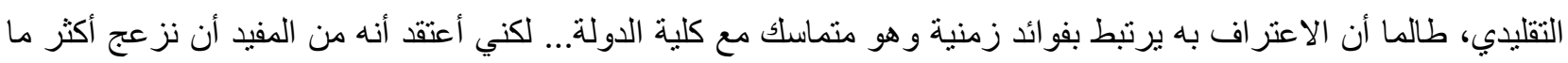

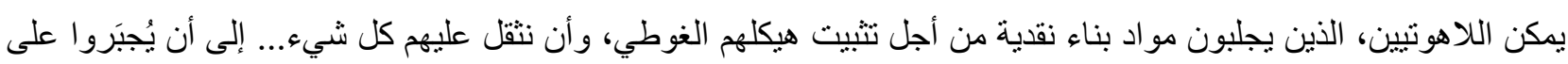

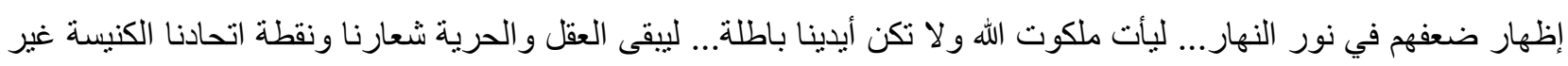

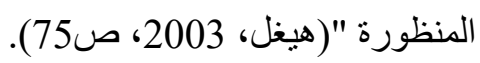

ومن الجدير بالملاحظة، ان المعضلة التي كانت تواجه هيغل، وغيره من الباحثين الاحرار في هذا الصدد، هي تلك التحالفات المقامة بين رجال الدين ورجال السياسة، أي بين السلطة الدينية، والسلطة الزمنية، اللذين كانا حليفين ضد حرية

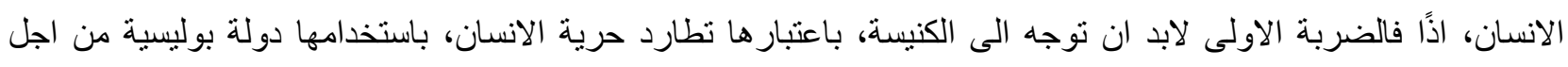

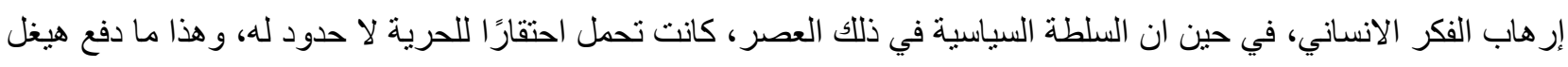
الى حملة على مبادئ الدين المسيحي، من خلال تحليل مفهوم الدين، و إستبداله بمفهوم آخر، مفهوم سهل الإدر الك، مفهوم أكثر دقة في تزويد المؤمنين بغذاء روحي، لأن المسيحية غير قادرة على أن تكون دينًا شعبيًا؛ و السبب في ذللك هو الكنيسة، التي شوهي هت

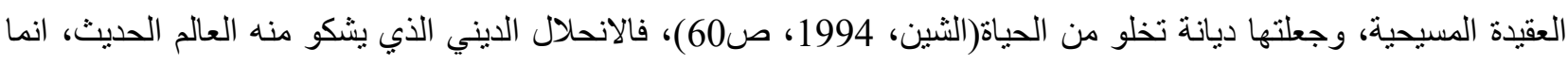

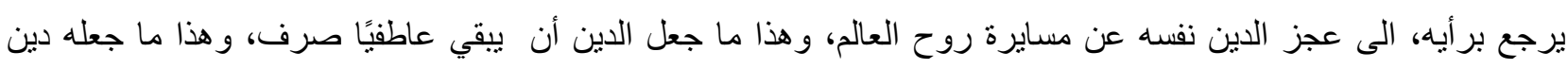

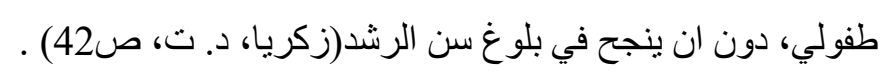

يرى هيغل ان دين الطفولة، أو بالأحرى الروح الطفولي في الدين، يرى الله سيدًا قادرًا، له ميوله واهواؤه ومزاجه، ورلا يجازي او يعاقب دائمًا حسب قاعدة الحق، فيخاف من هذا الاله اكثر مما يُحب، ويُقدم له أجمل عطايا الطبيعة؛ كضربة اختيارية ئرية للنقة و الفرح، و المخيلة الطفولية تعتقد ان هذا الإله هو اقرب هنا او هناك، وانه يقدس بنوع خاص هذه الأمكنة او هؤلاء الناس،

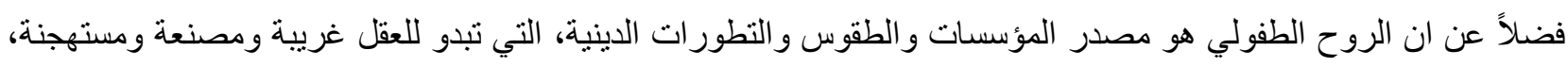
لكن هذه المؤسسات و الطقوس تصبح قابلة للإنهيار، بعد ان تتحرف ويتخلى عنها الروح، وبالأخص بعد ان بتقدم العقل ويكتسب لئب مزيدًا من المجال، و هذا يعني ان قلة الوعي، وكما عبّر هيغل عنها بالوعي الطفولي، هي سبيًا في ذلك، لكن يمكن تجاوزها من بن

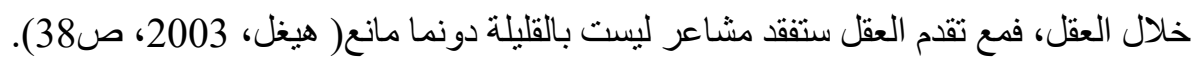


يمكن لنا القول بأن هيخل الثـاب قد خرج من سطوة الفلسفة الكانتية؛ عندما كتب بحثه الموسوم (روح الديانة المسيحية ومصير ها)، الذي تطرق به الى الروح اليهودي ـ الذي سنتحدث عنه بعد قليل ـ ومن ثم طرح فكرة (الحب) او المحبة، بوصفها

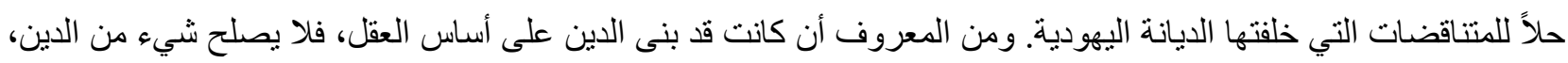
إلا ما يوجبه العقل. ووصل الى نتيجة مفادها، هي أن الدين خادم للأخلاق، وطرح من خلال كتابه (اسس ميتافيزيقا الأخلاق) مفهوم الواجب، وعدَّ القانون الأخلافي موجودًا فعليًا خارج الإنسان، ويستطيع الأخير الوصل إليه بواسطة العقل، اذن فالدين

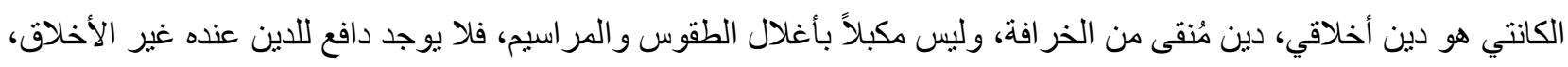

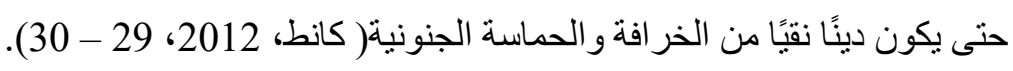

لذا فقد رأينا أن وزن النظرية الكانتية في تفكير هيغل، يزداد بوضوح خصوصًا عندما انتقد الديانة المسيحية، و عندما

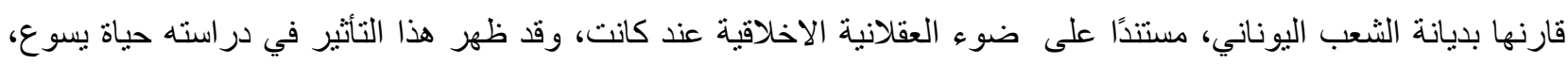

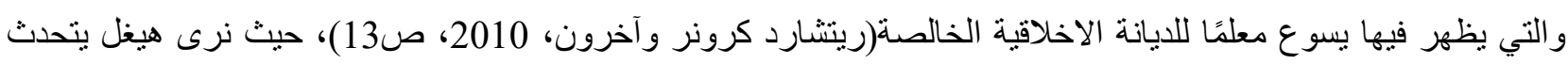

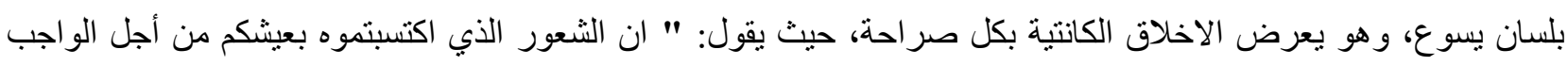

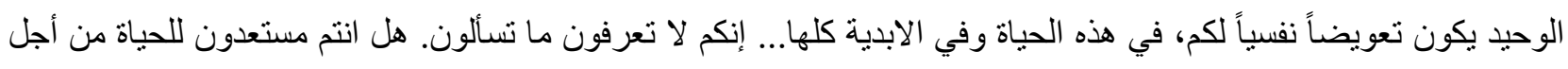

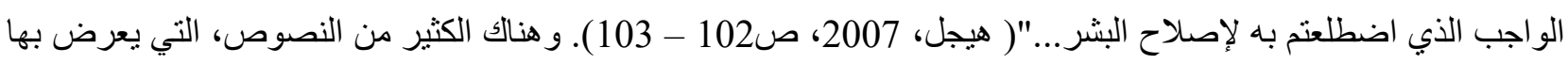
هيغل يسوع مرتديًا ثُوبًا كانتيًا، التي لا مجال لذكر ها.

لكن هذا الأمر لم يستمر طويلاً، فسر عان ما نجد أن هيغل يفترق عن كانت، في أكثر من نقطة. وأولى هذه النقاط هي اعتماده مفهوم (الحب)، و الذي يقول عنه هيغل: " إن الحب يوحد بين الذات والموضوع، بين الحرية والطبيعة، بين الفعلي هي هني

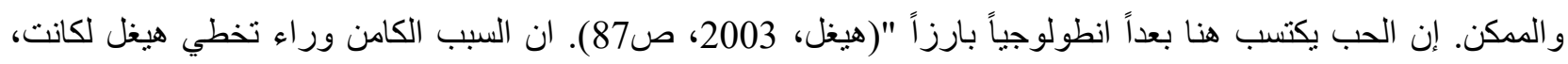
يستند الى فكرة الحب؛ وذللك من اجل معارضة اولئك الذين يجعلون من الله موجودًا متعاليًا ومطلقًا، يحيى لذاته، دون ان تكون له ادنى علاقة بالبشر، فيقرر على العكس من ذلك، ان الله محبة، وبذلّ للذات، وان فعل الايمان انما هو تحقيق لهذه الصلة الفعلية بالله، وتبعًا لذللك، فان المسيحية تصبح في نظر هيغل، ديانة المحبة التي تؤكد علاقة الله بالإنسان، و علاقة الانسان بأخيه الانسان، وليس انجيل المسيح مجرد انجيل الابوة الالهية، وانما هو ايضًا انجيل محبة القريب( زكريا، د. ت، ص54 - 55)، وهذا على بلى الضد من (كانت) جملة وتفصيلاً؛ لأن كانت كان يرى ان الانسان، ما هو إلا فاعل اخلاقي مستقل الارادة، وان عقله العملي الخاص، هو الذي يُشرّع القانون الخُلقي، فالإنسان هو سيد نفسه، لكن تللك بالضبط هي المشكلة؛ فلأنه ينبغي عليه ان يكون سيد نفسه، فهو لذلك ليس حرًا حقًا، بل هو منقسم نصفه حر ونصفه عبد( ريتشارد كرونر و آخرون، 2010، صونيط هون). لقد تغلبت رسالة يسوع على هذا الانقسام، ووحدت الانسان من الداخل، وتلك هي مضمون فكرة التكفير من الخطيئة و الفداء، بواسطة الحب الالهي، فالاخلاق الجديدة التي وعظ بها المسيح ليست اخلاقًا عقلية (كأخلاق كانت)، بل هي اخلاق المحبة؛ و هذا ما جعل هيغل يرى في المحبة قدرة على تحقيق ما لا يستطيع العقل تحقيقه، فالمحبة ليست قادرة على تحقق انسجام 
الانسان مع الانسان فحسب، بل قادرة ايضًا على تحقيق انسجام الانسان مع ذاته، ولهذا فأن فكرة الحب الثامل لدى هيغل، تحمل كل سمات ميتافيزيقاه المقبلة؛ فهي تهذف الى مصالحة الأضداد، وتحاول التغلب على كل من العقلانية والانفعالية و التجريبية ذات الجانب الو احد( ريتشارد كرونر واخرون، 2010، ص21 - 22)، و هيجل ينتقد كانت قائلاً: أن " هذه المثالية تسقط في التناقض لأنها تؤكد بوصفه حقيقة مفهوم العقل المجرَّد "(هيغل، 1978، ص36). ان السبب وراء رفض هيغل لواجب كانت، هو ان

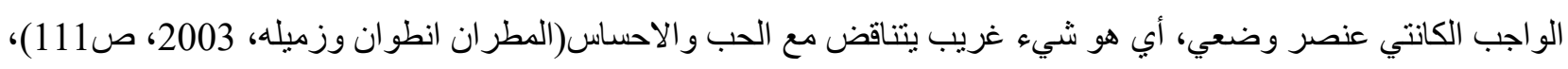
و هذا نر اه صريحًا في بحثه (روح المسيحية ومصير ها): " ان كل واجب وكل وصية يعلنان عن ذاتهما كثيء غريب من جهة، لكنهما كمفهوم امر ذاتي، يخسران بفضله من حيث انهما انتاج قوة انسانية، اي قوة الكلي او العقل، موضو عيتها ووضعانيتها و ارتباطهما بشيء خارجي... "( هيغل، 2003، صأ111). وهكذا تجاوز هيغل الواجب الكانتي بالحب، ولعل فكرته عن الحب، جاءت من تأثر هيغل بالبيئة الادبية التي كان يعيش أجو اهها حيث المذهب الرومانسي الذي بدأ بنشر أفكاره.

\section{نقد مفهوم الاين عند فلاسفة التنوير}

لقد هاجمت فلسفة التنوير العقيدة المسيحية؛ اي الايمان الذاتي والموضوعي معًا، فقضت على سلطة الايمان كما تقرره الكنيسة، فضلاً عن أنها أوّلت الكتاب المقدس، وبدأت بإعادة تفسيره فيما يتفق مع العقل والاخلاق، لتكون بذللك لاهوتًا عقليًا، و انتهت الى مذهب التأليه، ورفضت المعجزات وكل ما يتنافى مع العقل، ومن ثم أنكرت الله المشخص، و العقائد الثبيئية وكل

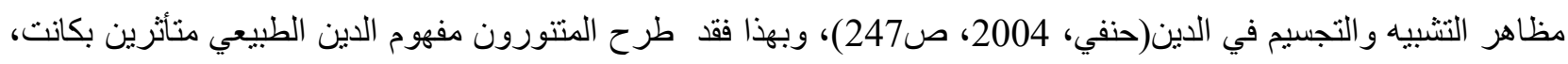
وكان هيخل متأثرًا على حدٍ كبير بفلسفة التنوير، ومفاهيمها بشأن الدين، وكان هذا واضحًا من خلال كتابات الثباب، التي كانت تفصح عن تأثره (بلسنج)، علاوة على ذللك، وجدناه في بحثه (حياة بسوع) وهو يخطو خُطى المتنورين، فلم بعد بسوع إلا بشرٌ كسائر بقية البشر(هيغل، 2007، صنائره) (رلج).

لكن هيغل لم يستمر بتأثره هذا، فقد قام بردة فعل عنيف، ضد النزاعات العقلية الجامدة، ورفض أيضًا مآثر فلسفة

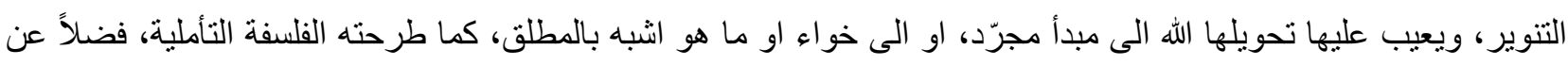
أنه يرى أن فلسفة التنوير قد صغّرت من شأن المطلق، بتصوير ها له في اقصى درجات التجريد، في حين هيغل يريد الابقاء على العقيدة كحقيقة خالدة وكو اقع تاريخي(حنفي، 2004، ص248). يقول هيغل: " يجب حسب رأيهم البقاء عند الدين، و الدين يجب ان ييقى عند الاعتقاد او الايمان، والشعور او العاطفة، واستشعار غامض لموضوعه، وان لا يطهح الى معرفة عقلية للحقيقة. حسب رأيهم، المعرفة لا تطبق على المطلق، على الله، وعلى ما في الطبيعة وفي الروح من مطلق... ان الفلسفة، منذ الزمن الذي بدأت فيه تحتل مرتبة مميزة في ألمانيا، لم تحصر قط تحت هيئة كئيبة كهذه، لأنه لم يحدث قط ان اتخذ مذهب كهذا،

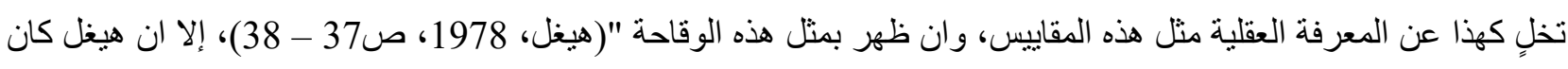

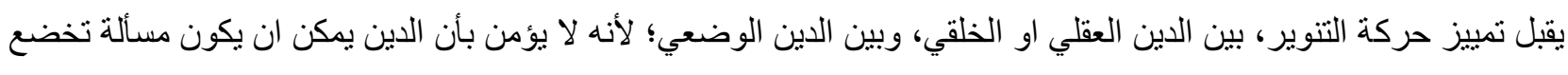
للاستدلال النظري، فالدين هو من شأن القلب، وهذا ما كان يردده دائمًا، وان استفادة الدين من الذهن نسبية ومحددة، لأن وسائل

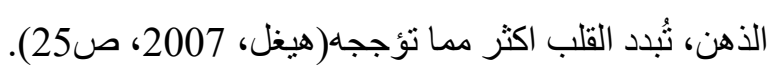

إن المأخذ الكبير الذي يأخذه هيغل، على فلسفة التنوير، هو أنها لم تنجح في ادر الك المضمون الحقيقي للدين، وهي بذلك بقيت تعاني العجز عن فهم الوعي الإنساني، الموجود لدى الإنسان عن لا نهائية وجوده، والحق أن فلاسفة التنوير لم يقتصروا 
على اقامة تصدع بين المتناهي واللامتتاهي فحسب، بل هم افرغوا اللامتناهي من كل مضمون حقيقي. صحيح أن هيغل برى بأن فلسفة التنوير قد قامت بدور ايجابي، عندما نقدت الايمان الديني؛ لأنها بذلك قد قضت على الخرافات و العبادات الوثنية، التي

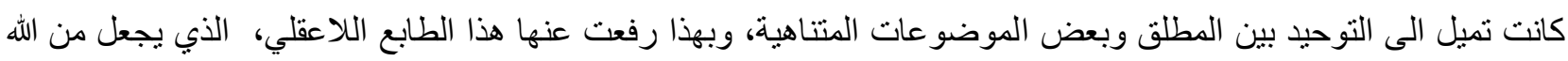
مجرد و اقعة جوفاء، او حقيقة مجهولة، ومهما يكن من شيء، فأن الحصيلة النهائية التي خرجت بها فلسفة التنوير، من نقدها للايمان الديني، لم تكن في الواقع سوى حصيلة هزيلة تافهة؛ لأن هذه الفلسفة لم تلبث، ان انتهت الى القول بنزعة مادية، لا تعترف بحقيقة اخرى سوى حقيقة المتناهي، هذا من جهة، ومن جهة اخرى انتهت بنزعة نفعية، لا نرى امكان قيام علاقات اخرى بين الافر اد، الا تلك العلاقات الخارجية، التي يكون فيها كل فرد مجرد وسيلة او وساطة(زكريا، د. ت، ص355 - 357).

\section{الاين الموضوعي والدين الأتي}

من المفاهيم التي صاغها هيخل في كتابات الثباب اللاهوتية، هما مفهومي (الدين الموضوعي) و(الدين الذاتي)، وقد تناول هيغل هذين المفهومين في بحثثه (دين الشعب)، وكان بذلك قريب من مفهومي كانت للدين، وهما (الدين الظاهري) و (الدين الباطني) الذي تحدث كانت عنهما و عن علاقتهما بالأخلاق، مُنتقدًا في ذلك الدين الظاهر و الذي يسميه دين الكنيسة، أو دين المؤسسة. وقد سار هيغل على خُطى كانت، وأر اد ان يُشير الى ان الدين الموضوعي، لا يمكن نو افقه مع العقل؛ لأنه يعبر عن خطا في الو اقع، وبالنتيجة فأن هذا الدين لا يتضمن اي حقيقة بالمعنى الدقيق لهذه الكلمة؛ والظاهر ان الهدف الرئيسي بالنسبة

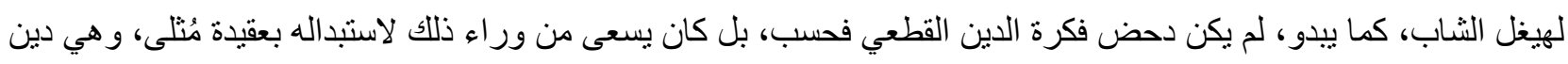

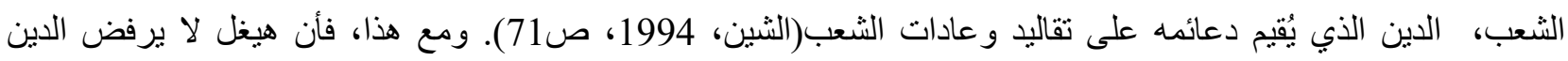

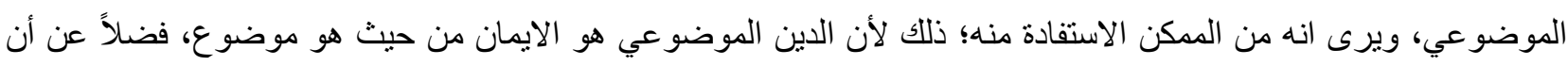
الفهم و الذاكرة، هما القوتان اللتان تبحثان في هذا الموضوع وتفحصانه، علاوة على ذلك، فالدين الموضوعي قابل لأن ينظم في الر أس، او يتخذ شكل نظام او يُعرض في كتاب(المطران وزميله، 2003، صرة 26)، لكن في نفس الوقت، يعتقد هيغل ان الدين الموضوعي، بهذه الطريقة سيسجن العقل في اطار صارم ومحدود، فضلاً عن أنه سير غمه على السير في طريق ضيق، تسوده التصور ات الوهمية المرعبة، في الوقت الذي لا ينبخي فيه ان يكون فيه مجال لعقل محدود، وفي الوقت الذي يجب ان يخلو فيه هذا المجال من التصورات الحسية، وألا يكون لنطوره نهاية(الثين، 1994، ص696)، فيقول هيغل بهذا الصدد " على العقل ان يتخلى للقب في المجال الديني. ولهذا فان افضل عقيدة تملأ القلب دفئًا. هي العقيدة الذاتية "(هيغل، نقلا عن الثين، 1994، ص69). و هذه اشارة واضحة، لوقوف هيغل بجانب الدين الذاتي وتبنيه.

لقد اخذ هيغل مفهوم الدين الذاتي عن فنشته وروسو معًا، وهو يظهر من خلال المشاعر و الاعمال، فاذا نسب الدين بهذا المعنى الى كل انسان، فذللك لا يعني أن هذا الإنسان يمنلاك معلومات دينية كبيرة، ولكن قلبه يشعر بأعمال الله، وعجائبه وقربه منها، فهو يرى الله في طبيعته وفي قدر الناس، و هو يسجد له ويشكره ويمجده في جميع أعماله، لأنه يسعى دائمًا لمرضاة الله، فهو لا ينظر الى عمله من مقياس الخير، بل من مقياس رضا الله. إذن فـ " الدين الذاتي هو كل القضية، وان اللاهوتيين يختلفون حول العقائد التي تخص الدين الموضو عي. لكن حين اتكلم في الدين، فإني استنتي كل معرفة علمية او مينافيزيقية لله ولعلاقتنا و علاقة العالم بها، لأن مثل هذه المعرفة هي شأن الفهم وهي بالتالي لاهوت، وليست ديناً. إن الدين الذاتي يتضمن معلومات عن الله وخلود النفس بمقدار ما تقتضي حاجة العقل العملي بذلك "(هيغل، 2003، ص26 - 27)، ويبدو ان هيغل يحاول هنا التوفيق بين الدين 
الذاتي و العقل، على إعتبار أن العقل بالنسبة لهيغل لا يتناقض مع الدين بالمعنى الذاتي، فضلاً عن أن كلٌ منهما يعمل في مجاله الخاص، ويعتبر هيخل الاحاسيس التي يستقبلها الناس عن طريق الكنيسة، ما هي إلا احاسيس موضو عية، ومن هذا المنطلق فأن الضرورة تستدعي العقل؛ للتدخل من أجل تحرير القلب، من هذا النوع من الاحاسيس، فضلاً عن تطهير الدين من الاحاسيس المادية(الثين، 1994، صورك). المثل الاعلى لايانة الشعب

كان هيغل بعتقد بأن الدين بشكل عام، بما فيه الدين المسيحي، في ألمانيا كان ذا تأثير سلبي، فقد لاحظ جمود الكنيسة، وخمول الثعب وتعلقه بالخر افات، فضلاً عن عدم اهتمامه بالثأن السياسي، علاوة على هذا، فقد كان هيغل، من جهة اخرى، معجبًا بالمدينة اليونانية القديمة، وبدور الدين فيها، الأمر الذي دفعه الى التساؤل عمّا إذا كانت المسيحية مؤهلة للنّ تكون دينًا

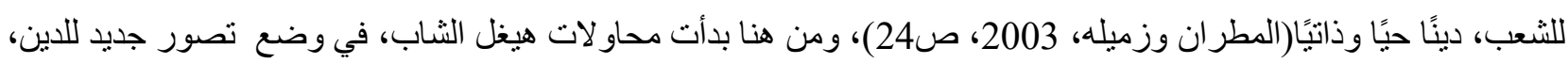
في اطار يختلف تمامًا عن تصور الكنيسة، التي جعلت العقيدة دينًا استبداديًا، الأمر الذي دفعه للتمبيز بين نمطين من الدين، هما (الموضوعي) و(الذاتي). أما (الموضوعي)، فهو الدين الذي يهتم بالأمور الظاهرية، وهو في إعتقاد هيغل دينًا مفروضًا على لإنى الإنسان من الخارج، في حين ان (الدين الذاتي)، وهو النقيض للدين الموضوعي، كونه دينٌ ينبع من قلب الإنسان، و هو على هيئة

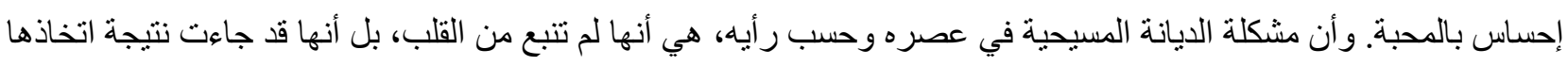
كدين موضوعي، في الوقت الذي هي في الواقع، اسسها المسيح عقيدة ذاتية، فهي لا تهتم بالعقل فحسب، و انما تشمل باهتمامها

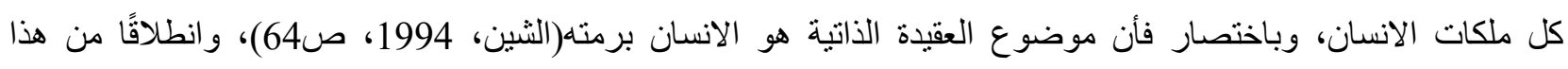
الاساس، فقد اعتبر هيغل اعتبارًا اساسيًا، يؤدي الى الاعتقاد بأن تصوره للدين الشعبي، أي الدين الأمثل الذي ينبغي أن يعتنقه الثعب، هو الدين الذي ينزل ملكوت الله على الارض، متأثرًا بالمدينة اليونانية، التي طالما كانت محط إعجابه في فترة الثباب،

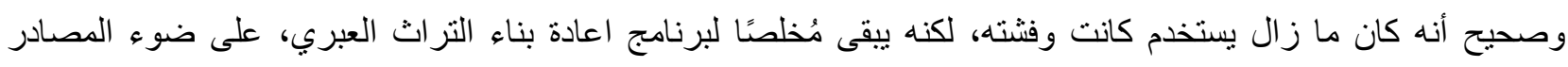

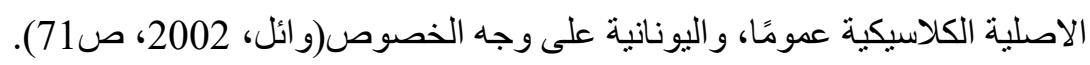

بما أن هيغل كان يعتقد، بأن الدين واحد من أهم شؤون الحياة، فمن هذا المنطلق، فقد كان غرضه هو بناء (دين انساني)، والغاية من ذلك هي تجنيد العقائد التي تستدعي القلب، وتجعل الثعب اكثر سعادة و افضل تنظيمًا إجتماعيًا

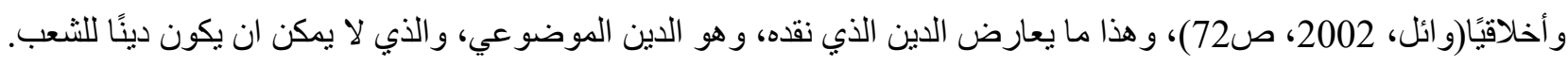
يقول: أن " الدين الموضوعي هو ذلك الدين الذي يخضع لمنهج ويقدم في كتاب، وينقل شفوياً الى الاخرين "(هيغل، نقلا عن الثين، 1994، ص65)، في حين ان الدين ينبغي ان لا نتعلمه من الكتب، او من يحصر نفسه في العقائد والذاكرة والقو اعد الاخلاقية، وينبغي أيضًا ان لا يكون ديانة لاهوتية، إذن لابد ان يكون الدين شعبيًا، وليس دين كهنونيًا، فهو ليس دينًا خاصًا بكنيسة معينة، بل هو دين للشعب ككل، فضلاً عن ذللك، يجب ان يكون مختلفًا عن ديانة الصليب المقبضة، فلا يمجد العذاب لاب لابل

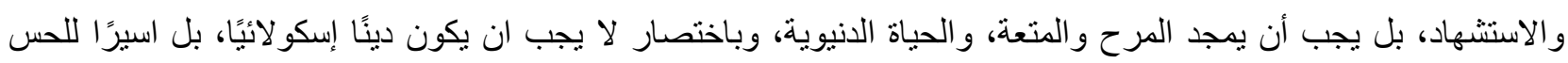
الجمالي، كما كان الدين عند اليونان من قبل(ريتشارد و اخرون، 2010، ص10 - 11)، وحتى " أعياد اليونانيين الثعبية كانت

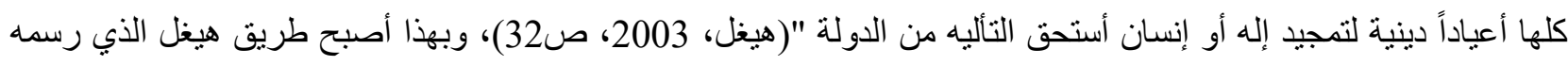
و اضحًا، وهو اكتشاف الطريق الذي ينبخي أن يسلكه الدين، من أجل تعزيز القدرة الاجتماعية الفعالة، وهو لا يكتفي بأن يهتم 
اهتمامًا تجريديًا بطرق انصهار الدين، في المجتمع والتاريخ، بل كان يطمح ان يستخدم سلطة الدين لإعطاء شكل جديد لمجتمع عصر التنوير الذي يعيش فيه(و ائل، 2002، صائرئ)، وهذا ما جعله بطرح فكرة الدين الذاتي، بديلاً من دين الكنيسة (الدين

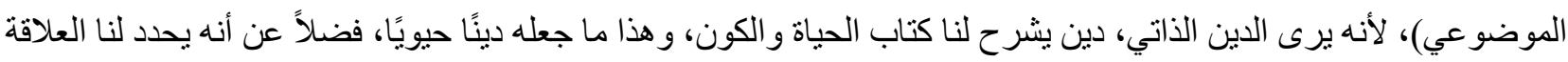

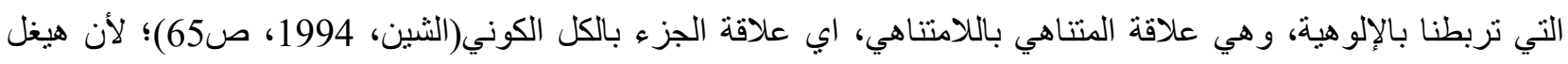

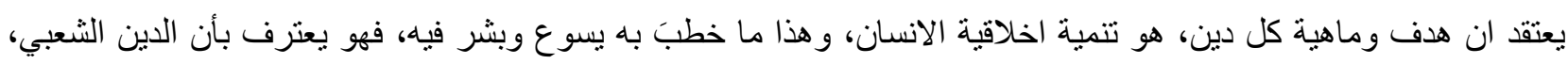

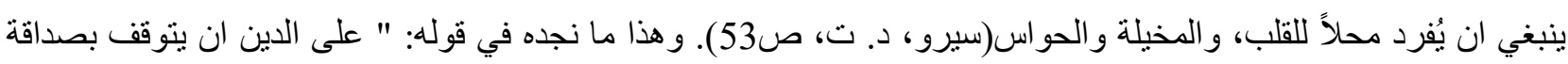

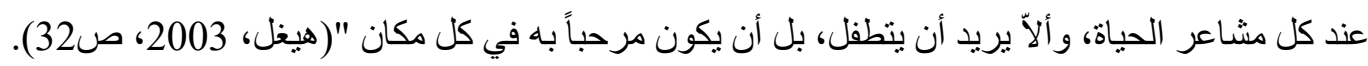

وقد يرى البعض في محاولة هيغل هذه، محاولة لغاية سياسية، وهي بناء مدينة لأبناء دين انساني، أو ذاتي وهو في الوقت نفسه تأسيس لدين سياسي؛ أي دين ذاتي وشعب اكثر سعادة(وائل، 2002، صايري 72)؛ لكن وبنفس الوقت، رفض هيغل تحويل الكنيسة إلى مجتمع سياسي، صحيح ان للدين قاعدة وظيفة، ولا ضير في أن تكون قاعدة للدولة، لكن ان تصبح هي الدولة، أو المُشرع لها، فهذا ما رفضه هيغل؛ لأنه يرى أن وظيفة المجتمع الكنسي، هي خدمة الثعور الديني(ميثم، 2012، ص125)، ولهذا كان تفكيره في مقالته (وضعية الديانة المسيحية) تفكير يحمل العداء للمسيحية ، وعلى الأقل العداء للنظام الكنسي، وان دل هذا على شيء، فهو يدل على تأثر هيغل الثاب وشغفه بالديانة اليونانية من جانب، ومن جانب آخر نأثره

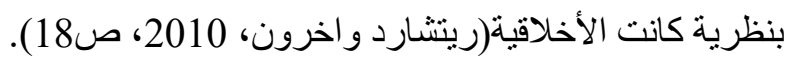

شخصية يسوع برأي هيغل

من مؤلفات الثباب المبكرة لهيغل، كتاب أسماه (حياة يسوع)، الذي قدم فيه يسوع بروح كانتية، فضلاً عن ذلك فقد قدمه على أنه معلم للأخلاق، ويتحدث هيغل بلسان يسوع و هو بذلك ينسب تأكيدًا للأخلاق يشبه تأكيد (كانت) لمؤسس المسيحية

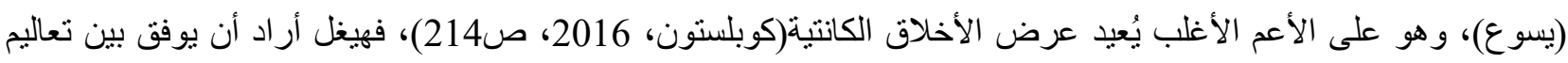

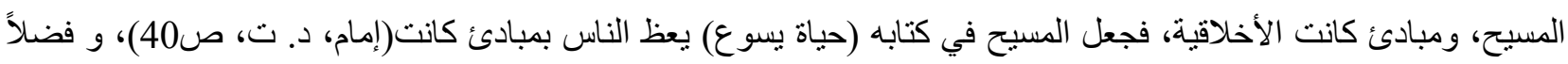
عن هذا فإن هيخل قدم يسوع، بصورة مجردة عن جميع المعززات، فيسوع هيغل ليس ابن تللك المعزة التي نعرفها، بل جعل له له

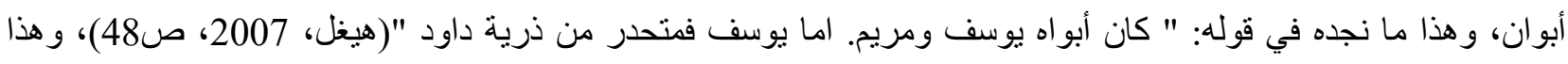
يخالف الاعتقادات السابقة، التي ترى يسوع شخصية مختلفة، فمع هيغل اختلف الأمر و أصبح يسوع رجل مبشر بالقيم الأخلاقية، فهو ليس ابن المعزة التي نعرفها جميعًا، و انما بشرٌ مثلنا، ولد و لادة طبيعية، ومارس حياته كما يمارس الناس حياتهم.

ان هيغل تناول شخصية المسيح بروح علمية فاستبعد كل المعجزات، فيسوع أحد أبناء قرية بيت لحم اليهودية، وينحدر من عائلة يهودية، وتربى في حضن اليهودية، وحتى أنه قد حُنت حسب شريعتهم، فحياته كما عرضها هيغل، هي حياة بسيطة، معتمدًا في ذلك على الحقائق المعقولة الواردة في الاناجيل، الأمر الذي جعل هيغل يبعد عن شخصية المسيح، الجانب الالهي، و هو بذلك ابتعد عن المسيحية السُّنية(الرسمية)، ونظر ليسوع على أنه رجل ساحٍ مكافح من أجل الفضيلة والحرية(بدوي، 1984، ص572)، ويقول هيغل بلسان يسوع: " لا نظنوا أنني جئت بالصدفة لأكرز ببطلان الثرائع! ما جئت لأبطل الخاصية الالزامية

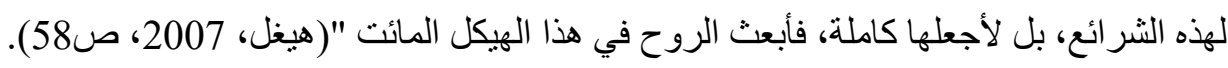


يرى هيغل ان المسيح، كان أول من ثار ضد المجتمع في عصره؛ من أجل تحرير الإنسان، والتبشير بعقيدة ذاتية،

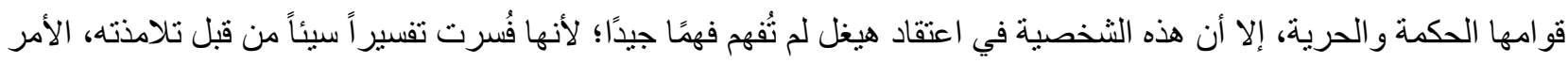
الذي جعلها تصبح على نقيض تصوره الأخلافي للعالم؛ فالمحور الأساسي ـفيما برى هيخل- الذي تدور عليه جميع التعاليم

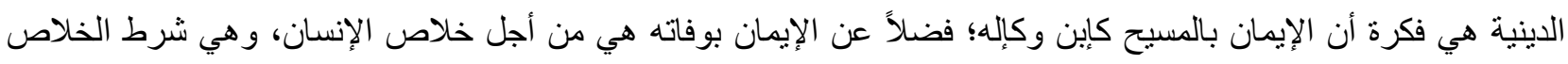

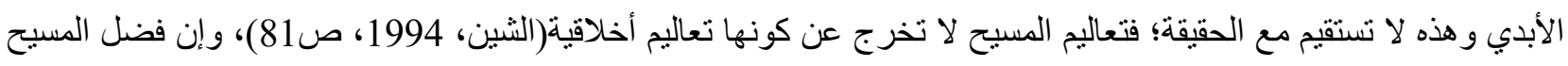
في رأيه كبير " لأنه أصلح مبادئ البشر الفاسدة، وعرّفهم بالخلقية الحقيقة وعبادة الله المستنيرة "(هيغل، 2007، ص47 - 48)، ولهذا نرى هيغل يقدم المسيح كمؤسس لديانة الاخلاق، و العقل، وكمفكر إنساني، فيسوع لم يتوقف عن النقد لعادات شعبه السيئة،

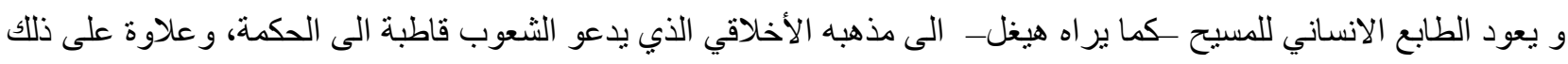
رغبة يسوع في بناء مجتمع إنساني، يُحكم بالقانون الثرعي للأخلاق المطلقة، تلك هي الأخلاق التي لا يتميز بها إنسان عن آخر(الثين، 1994، ص94). ولو تتبع القارئ القصص التي ذكرها هيخل في حياة يسوع، لوجد الكثير من التعاليم الأخلاقية التي يذكرها هيغل بلسان يسوع، و من بين القصص، سؤ ال بطرحه أحد الاشخاص على يسوع، و اصفًا إياه بالمعلم الصالح، فيجيبه

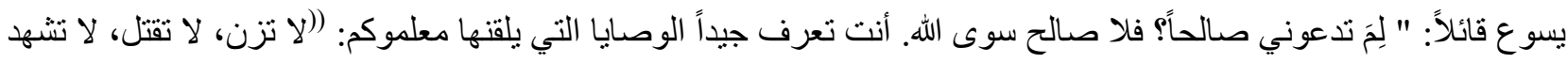

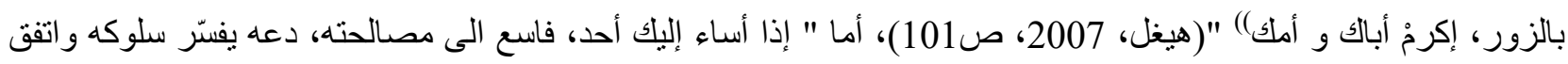
معه "(هيخل، 2007، ص83). و هناك الكثير من النصوص التي لا مجال لذكرها، والتي تعتبر تعاليم اخلاقية بحتة، يُعلمها المسيح لأصحابه و تلامذته، ويرسم لهم طريق الفضيلة، حيث يقول: " من يرغب في إطاعة الفضيلة يجب أن يعرف كيف بلزم نفسه بالفقر. ومن ير غب في أن يبقى مُخلصاً للفضيلة بطريقة راسخة، يجب أن يكون مستعداً لتكريس كل شيء، حنى حياته، من أجلها! من يحب حياته الخاصة يفسد نفسه. ومن يحتقر حياته، يبقى مخلصاً لأناه الفضلى ويخلِّصها من متطلبات الطبيعة. أية قيمة

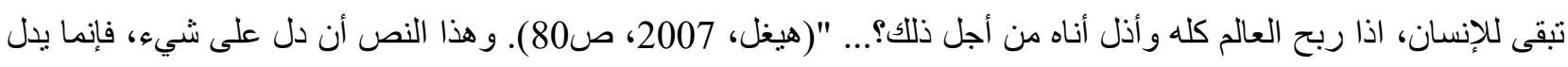
على النزعة الصوفية التي اظهر ها هيغل في كتابه (حياة يسوع)، فهي دعوة المسيح لحياة الزهد بالدنبا، و الإنتصار على الذات؛

من أجل أن يكون الإنسان إنساناً فاضلاً.

ومن الجدير بالذكر هو ان هيغل قد فارن في وقت سابق، بين سقراطو المسيح، في احدى كتاباته اللاهونية المبكرة،

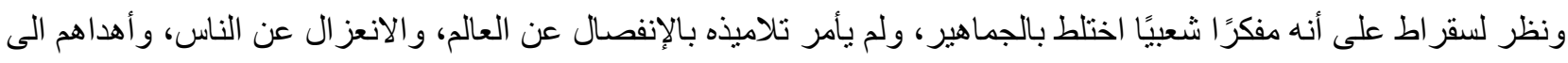
السبيل الذي يُنمّي شخصياتهم تتمية حرة، عكس يسوع المسيح، الذي قدم نفسه للناس على انه صاحب سلطة، وحامل رسالة

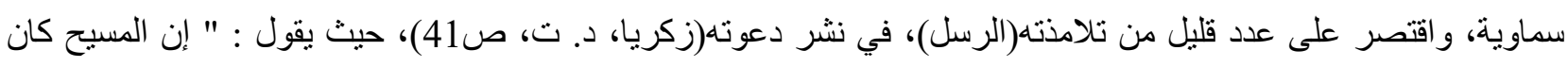

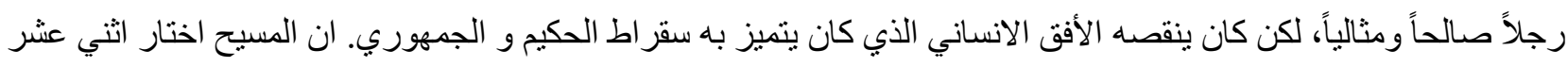
رسو لاً، نعمو ا بالتعامل الوثيق معه وبتعليمه... اما سقر اط، فكان له تلاميذ من كل نوع، او بالأحرى لم يكن له اي تلميذ. انه كان

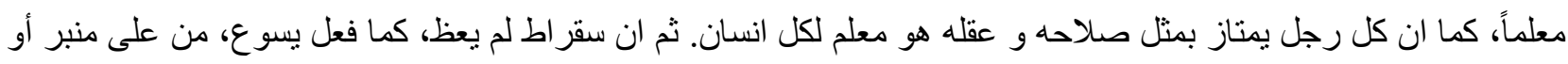
على الجبل، لأن فكرة الوعظ كانت غريية عن الثعب اليوناني "(هيخل، 2003، ص36 - 37). وقد علل هيغل وفي وقت لاحق

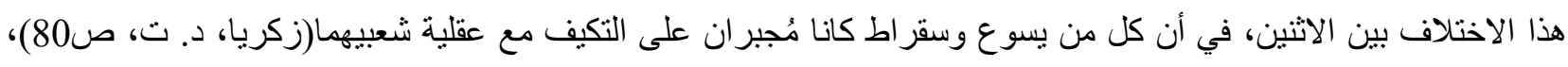
فيقول في هذا الصدد: " كان المسيح حكيماً مثل سقراط. وكلاهما كان يسعى من أجل تأسيس دين الفضيلة. كما أن كليهما كان يحاول نشر الاخلاق الفاضلة، وذللك بتبشيره بعقيدة تقوم على العقل "(هيخل، نقلا عن الثين، 1994، ص83) ويبدو مما سبق، 
ان هيغل لم يتأثر بشخص يسوع، ولكن نظر إليه كسقر اط، الذي كان له دور بارز في تربية الشعوب، ولهذا أسباب، أهمها هو بيئة

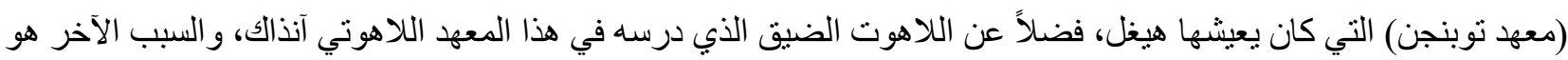

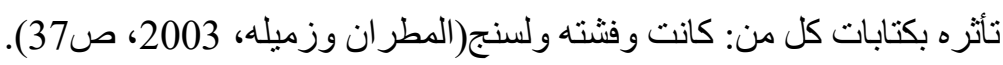

\section{نقد الإرث اليهودي في المسيحية}

ان الغاية التي يمكن إستتتاجها من خلال البحث التاريخي الذي قدمه هيغل، هي محاولته لإثبات ان الإنسان هو المصدر الأساسي لفكرة الالو هية، عندما كان ضعيفًا و تسحقه قوى الطبيعة، وهذا الأمر طبقه هيغل على الديانة اليهودية، فهي لم تتشأ إلا بسبب الضرورة، وان الأب الأول لليهود(إبراهيم)، كان وراء إختراع فكرة الكائن الأعظم(الله)؛ لأنه كان يراه هو القادر على ضمان سلامته، و هذا الكائن حسب اعتقاد ابر اهيم جدير بالعبادة، ولكن هيغل يرى عكس ذللك، فانبثاق الإله المطلق اللامتناهي من

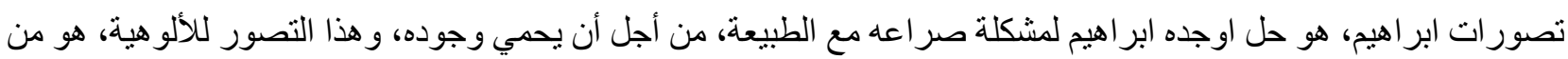
جلب الثقاء ليس لليهود فقط، بل وحتى اللاحقين بعدهم من أتباع العقائد الوضعية(الثين، 1994، صناعئ124)، وكما يقول هيغل: " إن روحه هي الوحدة، النفس، التي كانت تحكم قدر ذريته، وهو يظهر في أنكال مختلفة حسب القوى التي كان يصار عها، أو يتدنس بإقتبال كائن غريب عندما كان ينكسر بواسطة القوة أو الإغر اء "(هيغل، 2003، صوهي وهر) و هذا ما تناوله هيغل في مقالته التي تجرد فيها من سطوة كانت في بحثه (روح المسيحية ومصير ها)، و التي يذهب فيها هيغل ، الى ان الديانة اليهودية أصبحت أساس الثر؛ بسبب شر ائعها الأخلافية، لأنهم جعلو ا فارق كبير بين الله والانسان، عندما جعلو الأول سيدًا، والثاني عبدًا وتابع له،

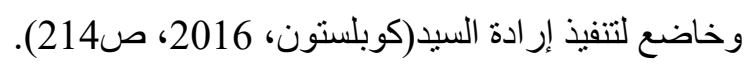

كان هيغل يعتقد أن تصور اللإله الأعظم قد إنبثق لأول مرة في الفكر البشري، بعد أن تجاوز الانسان الحالة الطبيعية، و هو ما نجده في مغزى قصة الطوفان؛ لأنها تمثل بداية الصراع الذي قام بين قوى الطبيعة التي تظهر عدائها وتسلطها من ناحية، وبين الانسان الذي تجرد من ثقته وعلاقته بالطبيعة من جهة اخرى( الثين، 1994، ص115 - 116)، ويضيف هيغل " لقد كان لحدث الطوفان على روح الإنسان مفعول الاحساس بالتمزق العنيف والجحود أزاء الطبيعة "(هيغل، نقلا عن الثشين، 1994، ص116). ويبدو ان هيغل هنا يقدم لنا مرحلة أولى، من مر احل الروح، والتي من المكن ان نسميها بالمرحلة الطبيعية، التي لإني عاش فيها الإنسان في خضوع واستسلام كامل لقوى للطبيعة، وبعدها عانت الروح في سكينة هادئة، ومن ثم جاء بعدها الطوفان في عصر نوح، الذي حطم الوحدة الأولى مع الطبيعة، وفكك عرى الصداقة بينهما، وأز ال السكينة التي كان يعيش فيها الانسان،

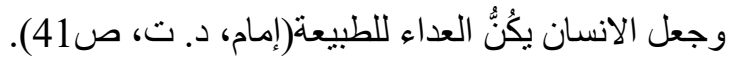

لقد كان هيغل يصف لنا حياة ابر اهيم، باعتباره نموذجًا للرجل اليهودي. ابر اهيم ذلك الرجل الذي وجد في حضرة الاله الاعظم حصنًا منيعًا يلوذ به، وما دفعه لذلك - بحسب هيغل- هو الوحدة القاسية، التي كان يعانيها، هي من دفعته الى تسليم حياته تمامًا لله(زكريا، د. ت، ص49)، و كان هيغل ينشد من وراء تاريخ ابر اهيم، إثبات ان فكرة الاله الأعظم، قد جاءت من الضرورة التي كانت تتسم بها الحياة ابراهيم الخاصة، وهي في الأساس من أجل أن يتجاوز التناقضات التي كانت تعترضه في تلك الحياة(الثين، 1994، ص119 - 120)، لأنه " كان غريباً على الأرض، إزاء الأرض كما إزاء الناس الذين كان، وبقي، فيما

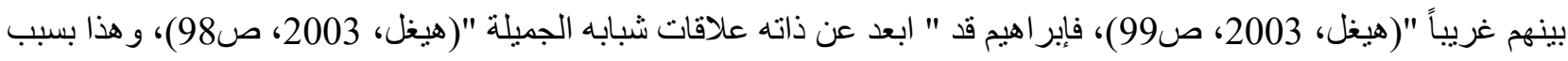
انفصاله، الذي مزق روابط الحب التي تربطه بالبشر و الطبيعة، بهذه الطريقة رفض الجد الفعلي لليهود الحياة العامة مع 
الآخرين، حتى انه، قد رفض زو اج ابنه من سيدة لم تكن يهودية، و هذا السلوك يتضمن إحتقارًا للطبيعة و للآخرين، هذا هو الإله كما يتصوره اليهود، إنه سيد لكل من الطبيعة و نسل إبر اهيم، ومن الجدير بالملاحظة، أن تحليل هيغل هذا لحياة ابراهيم، يعتمد

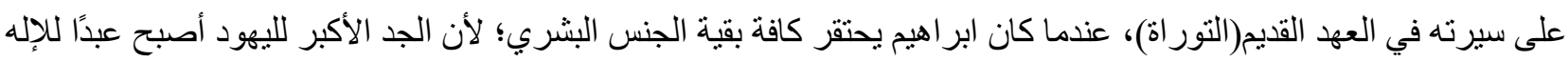
الاعظم، اي عبدًا -حسب رأي هيغلـ- لإله غريب عن الإنسان، إله لا ينتمي إلى الطبيعة، ولا يساهم في تصوره اي عنصر منها، و هذا ما جعله سيدًا لكل شيء(الثين، 1994، ص119 - 120)، والإله بهذه الصورة، سيجعل من الشعب اليهودي " بلا محتوى، فار غين، دون حياة وحتى غير مائتين"(هيغل، 2003، صهئ، 101).

لقد كان هيغل يعتقد ان صلة الرجل اليهودي بالله لم تكن صلة ايجابية تقوم على المشاركة، بل أنها صلة سلبية تقوم على العبودية، فلم تكن في الديانة اليهودية العلاقة بين الله و الإنسان، علاقة ذات بذات، بل علاقة موضوع بموضوع، وهذا ما دفع

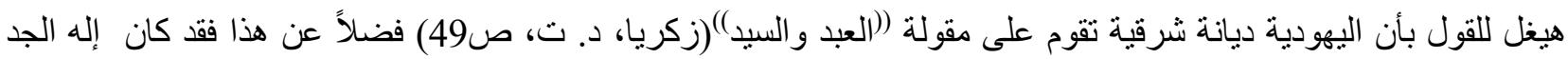
الاكبر لليهود - فيما يرى هيغل- لم يكن في النهاية سوى إله خاص، لا يشمل بر عايته إلا ابر اهيم و ذرتيه، و هذا ما جعل تصور الالوهية بهذه الطريقة نفيًا لفكرة المحبة، وتربة خصبة لزر اعة الكراهية والانفصال، وهذا التصور للالوهية كان أساس لبناء منظومة اليهود الأخلاقية، الأمر الذي دفعهم الىى صر اع مستمر مع بقية الثعوب، التي تسكن نفس المنطقة، وهذا ما يُخالف الفكر الإنساني جملة وتفصيلا، لأن شيطان الكر اهية جعلهم ينفصلون عن السكان المحيطين بهم، وهذا ما جعل اليهود في رأي هيغل ، لم يقدموا على محاولة إنشاء دولة في تاريخهم، إلا تحت وطأة وتهديد من الآخرين، وخوفاً من الفناء، وعلاوة على ذللك، فان اي دولة حاولوا بناءها لم يكن ذللك حبًا منهم في وحدة الانسجام في ظلها، بقدر ما هي محاولة منهم لحفظ أنفسهم و تجسيد افكار هم العدائية، و هذا يؤكده التاريخ - بحسب رأي هيخل- في أنهم كانوا انشقاقيين على انفسهم و على الآخرين، وهذا ما ورثوه من الأب الأول، وستستمر حتى آخر جيل من ذريته، وكما يقول هيغل: " أن هؤلاء يكونوا قد تصرفوا بغباوة، اذا غامروا بكامل إمكان الحياة وشرطها من أجل الواقع. ان هناك تناقضاً في أن يغامر بالوجود و الملكية من أجل الوجود و الملكية... (ويمكن التضحية) بالملكية والوجود فقط من أجل الشرف و الحرية أو الجمال، من أجل شيء أزلي. لكن اليهود لا يشاركون في أي شيء أزلي

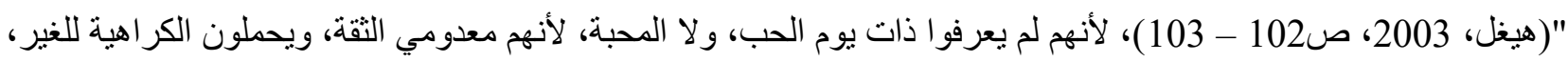
هذا ما دفع بهم لئن يكونوا عبيدًا خاضعين للآخر المثالي(الله)، و مع هذا فأنهم قد رفضوا تشريع موسى، ونكثوا العهد معه، فضلاً

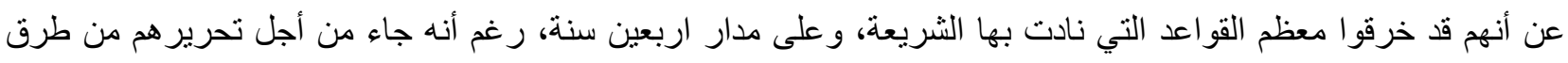
تفكير هم، وعبودية عاداتهم واخلاقهم(الثين، 1994، ص120 - 123)؛ لأنهم لم يكن لهم علاقات دولة حقوقية، فعاداتهم لم تكن غير المساواة في إرتباطهم بحاكمهم غير المنظور و عبيده، فعندما يُقارن هيغل بين دولة موسى و الدولة اليونانية، يرى أن الثانية

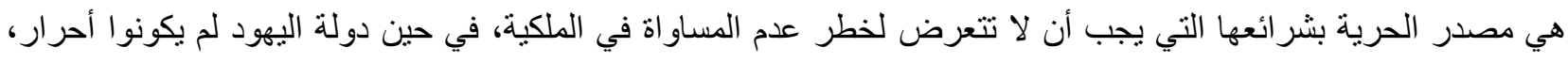
وليس لهم حقوق، لانهم يملكون كل شيء كإعارة وليس كملكية(المطر ان، وزميله، 2003، ص104)، وهذا ما يفصح عنه قول هيخل: " إن أولئك اليونانيين كان يجب أن يكونوا متساوين، لأنهم كانو ا كلهم أحراراً ومستقلين، أما اليهود فكان يجب أن يكونوا

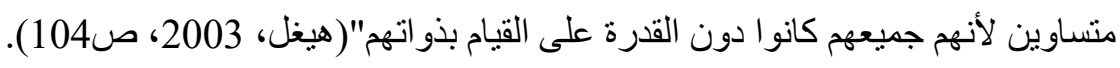

يعتقد هيغل ان الصر اعات المتعددة التي نزخر بها البشرية، وخصوصًا صراع الانسان والطبيعة، هو وراء فقدان الحرية و الوحدة هذا، فصراع الانسان قد حول الطبيعة الى قوة معادية له، الأمر الذي يتعين على الانسان ان يسيطر عليها، وهذا 
بدوره أدى الى قيام تعارض بين الفكرة والو اقع(هربرت، 1970، ص56)، فقد كان هيغل مرغمًا على اعتبار التفسير اليهوديالمسيحي لله، و علاقته بالإنسان، على انه مذهب يقوم على علاقة السيد بالعبد؛ لأنه يدافع عن طريق المشاركة في الحياة الالوهية،

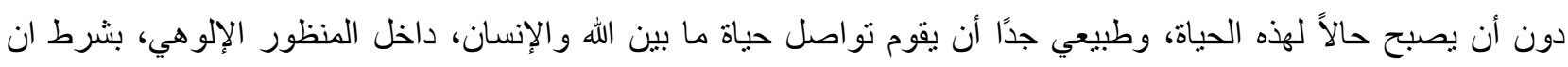
تحكمه دائمًا الر ابطة العلية بينهما، في حين أن هيغل، يُعرّف الدين بأنه سمو الانسان بذاته، او على أنه تطلع الانسان الى العلو ،

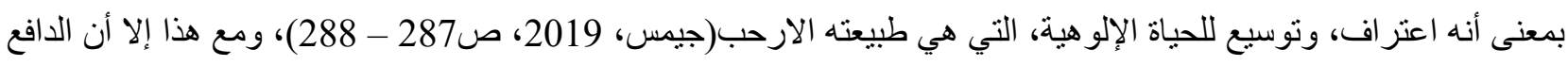
الرئيسي لحملة هيغل على الديانة اليهودية عمومًا، والتصور اليهودي للاله، ونقده لهذا التصور، هو انه دين يجعل الانسان عبدٌ خاضع، لا يعرف الحرية، وان الخلقية الحقيقية -حسب رأي هيغلـ- ليست اخضاع الفرد الى الكلي، بل أنها على أقل تقدير،

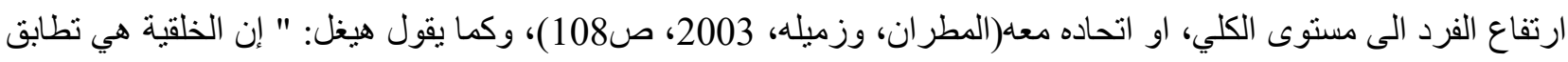

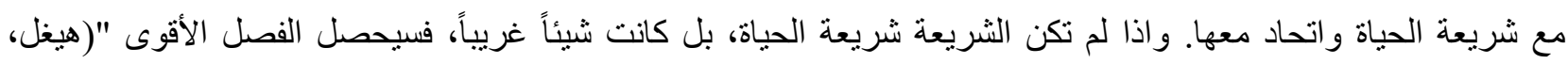

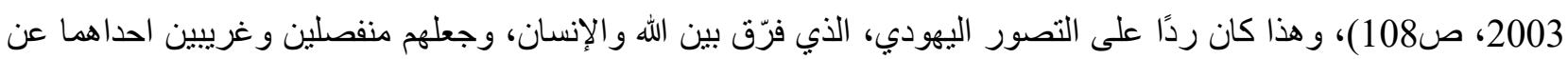
الآخر تمام الغربة، والدين بهذه الصورة هو اعلان ان الإنسان لا قيمة له، في حد ذاته، فضلاً عن أنه يستحق أن تقوم بينه وبين الله علاقة عبودية، ولهذا اعاد هيغل قصة نوح و ابر اهيم، من أجل أن تصوران الله على انه استجابة لحاجة الناس(جيمس، 2019،

(286)

لقد كان هذا واحدًا من المواضوعات المهمة الني تطرق إليها هيغل، من أجل إثبات أحقية و صدق رسالة المسيح، و المسيحية. و من هذا المنطلق، علينا ان نعرف النتيجة التي وصل إليها هيغل خلال عودته للتاريخ، و نقده اللاذع لليهودية. فقد الئه رأى هيغل ان تصور الإلو هية عند المسيحين، لم يكن يختلف في شيء عن تصور ها عند الأب الفعلي لليهود، وهذا الأمر هو من

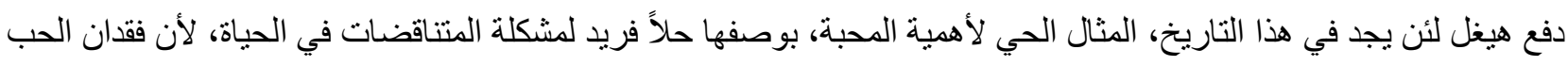
في تاريخ اليهود، هو من يقف وراء صفة الكراهية التي ميزتهم عن الآخرين، بإعتباره المصدر الأساسي لها(الثين، 1994، ص123)، وهذا ما دفع هيغل لئن يفسر المسيحية على ان لهاوظيفة أساسية في تاريخ العالم، وهي إعطاء الإنسان مركزًا مطلقاً جديدًا، علاوة على ذلك إعطائها هدف نهائي للحياة(هربرت، 1970، ص57)، ومعنى هذا هو خلاصًا للفرد من حياة الثقاء، التي سادت الديانة اليهودية، وهذا ما دفعه للقول بأن " الديانة الموسوية قد ولدت من الثقاء ومن أجل الثقاء. وليس من أجل السعادة التي يرغبها الإنسان، او من أجل إله غاية في الجدية... انها ديانة شقاء لأن الثقاء يمثل الانشقاق "(هيغل، نقلا عن الثين،

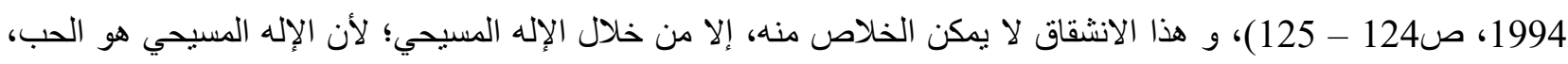

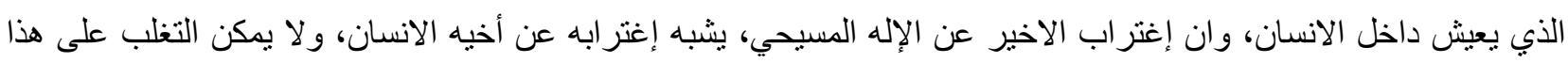

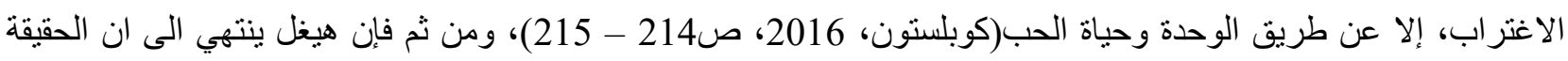
المطلقة، وهي الجمال الأخلاقي، الذي اكتشفها في الانجيل، تلك الحقيقة الانجيلية، التي تقوم على مبدأ الحب أو المحبة، فالحب هو الداء جمال القلب، الذي يجمع بين الروح اليونانية، و العقل الأخلاقي الكانتي، وهذا هو المركب الذي حققه بحث هيخل الموسوم ( روح المسيحية ومصيرها)، الذي أعلن هيغل من خلاله قبح اليهودية، تلك الديانة التي أخذت مكانة الدين المسيحي، فضلاً عن أن هيغل ير اها ديانة مضادة للجمال اليوناني(رنتارد كرونر ، واخرون، 2010، ص18 - 19)، ليُصرّ ح بعد ذللك، أن المحبة التي نادت بها المسيحية، هي حلاً لمشكلة الاضداد في الديانة اليهودية. 


\section{كتابات الشباب مصدرٌ لمفهوم المطلق}

لقد عرضنا أهم ما جاء في كتابات هيغل في مرحلة الثباب، وتوصلنا إلى نتيجة، بأن هيغل الثاب، كان في معظم هذه الكتابات ذا ميول دينية تنطلق من نأويل خاص به للمسيحية، وكما هو معروف، فإن المذهب الفلسفي المتكامل لهيغل، قد جاء

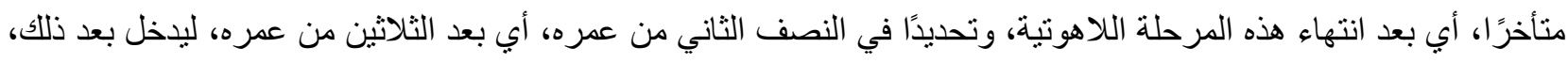
مرحلة مهمة مثلت مرحلة نضوج ذلك الثاب الذي كان ذا ميول دينية. ومن هنا لابد أن نتسائل، هل تذكر هيغل هذه الكتابات

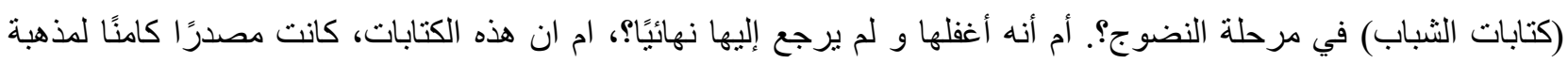

$$
\text { الفلسفي، لاسيما تصوره عن المطلق؟ }
$$

لقد كتب هيغل في عام 1800م بعض الملاحظات المهمة، والتي اعطاها (هرمان نول)(محرر مخطوطات هيغل اللاهوتية) اسم (شذرة مذهب)، في هذه المقالة يمكن أن نجد البذور الأولى لمذهبه، وهي الفترة التي عاش فيها هيغل في مدينة (فر انكفورت)، حوالي سنة 1800م، البذور الاولى لفلسفته في المطلق، فهيغل لا يزال يرى في الدين حلاً لمشكلة الأضداد،

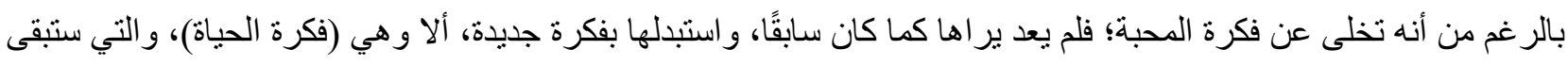
تؤثر في تفكير هيغل إلا أنها ظهرت في مذهبه النهائي، والتي يمكن أن نر اها في المنطق، بإعتبار ها مقولة من مقالات المنهج الجدلي، ووضع الدين في هذا المقال، في درجة أعلى من الفلسفة، حيث أنه اعتقد أن التفكير الفلسفي يقتل الحياة؛ ويمزقها الى بلى

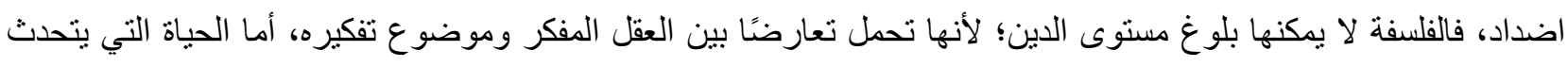
عنها، فهي تجمع نقيضها في جوفها، و هي في الوقت نفسه، لا يمكن الوصول اليها، إلا بالفهم و الفكر؛ لأنها ترتفع بذاتها عنهما. لكن ومع هذا فانن هيغل برى أن الفكر يمزق الوجود الحي، وهذه نظرة يجاوز ها الدين، حيث يمكن أن نرى الحياة المتتاهية هي

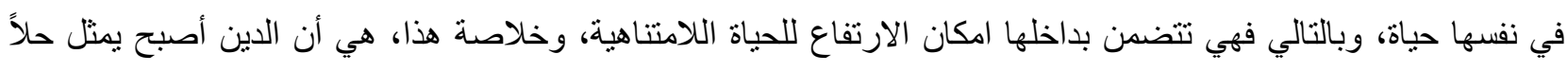
لمشكلة الاضداد التي واجهها هيغل، في حين الفلسفة عكس ذللك، فهي عاجزة عن الوصول لهذا المستوى؛ لأن هيغل يعتقد أن

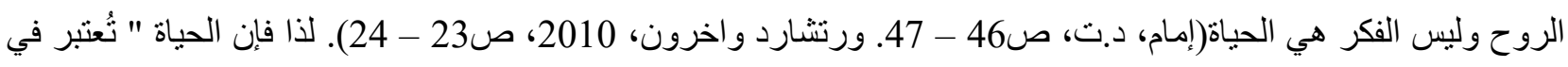

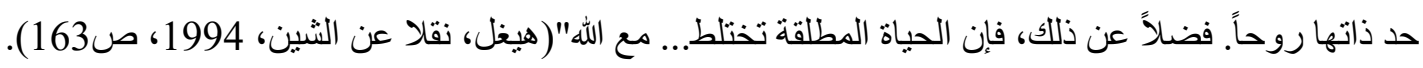

ويثير مصطلح الحياة عند هيغل الى الكل المطلق، والذي ظهر لأول مرة في مقالته (روح المسيحية ومصيرها)،

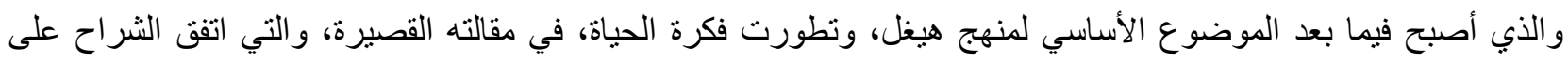
تسميتها (بمنهج فر انكفورت)، و هي ذاتها( شذرة المذهب) حسب تسمية نول. ومن الجدير بالذكر ان مصطلح الحياة عند هيغل، لا

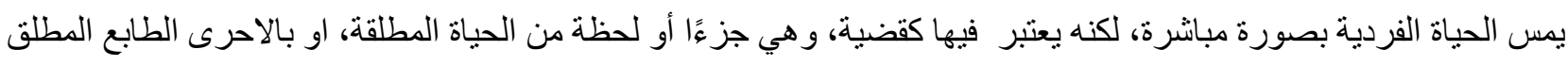
للكون، و التي لا يمكن أن تنفصل عنها حياة الفرد(الثين، 1994، ص162 - 163). ولعلنا نستطيع أن نفهم الدور الخاص الذي اعطاه هيغل لفكرة الحياة، إذا أدركنا ان جميع المتناقضات، في رأيه تتحل ولكنها تظل مع ذلك قائمة في العقل. فهيغل يتصور الحياة على انها روح، و " الروح وحدها قادرة على فهم وتضمن الروح "(هيغل، نقلا عن الثين، 1994، صعئ 165)، ومعنى 
ذلك، هو أن الروح قادرة على ان تشتمل في ذاتها على المتعارضات الشاملة في الوجود، فضلاً عن أنها تسيطر عليها، و الخلاصة هي أن هيغل يتصور الحياة على أنها مفهوم بدل على حياة كائن عاقل، ويدل أيضًا على صفة الانسان التي ينفرد بها لها

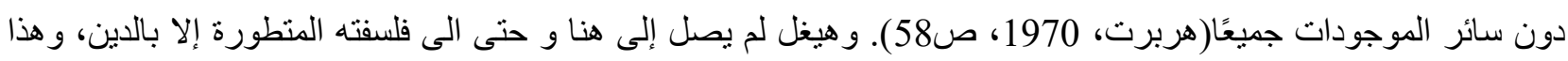
يدل على أن الفلسفة عند هيغل تقتصر عن الدين، فهي مساعدة وتابعة له، أما الفلسفة فهي تبين لنا ما ينبغي أن يكون عند تغلبنا على التضاد بين المتناهي واللامتتاهي، وهذا الأمر هو من جعل هيغل يطرح فكرة ان الحياة تسنطيع التغلب على الاضداد و المتناقضات، منطلقة من نقطة تمثل بدايتها، وهي حل التضاد بين المتناهي واللامتناهي، فلو أننا وضعنا أنفسنا في مركز المشاهدين، لأصبحت حركة الحياة جلية أمامنا، والتي تشبه الطبيعة الى حد بعيد، فهي كثرة عضوية لامتناهية من الأفراد

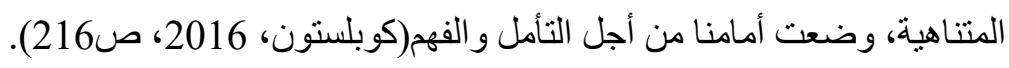

إذًا هيغل لم يتخلى عن التصورات التي قالها في فترة الثباب، وأنه قد وصل لمذهبه الفلسفي الناضج من خلال الكتابات اللاهوتية المبكرة، فمثلما كان الله هو الثاغل في هذه الكتابات، أعلن مجددًا في فلسفته الناضجة أن الموضوع الأساسي للفلسفة هو الله ولا شيء غير الله(ريتشارد واخرون، 2010، صهونه 122). ومنذ هيغل، أصبحت فكرة الحياة منطلقًا لكثير من المحاو لات التي ترمي لإعادة بناء الفلسفة، على موقف الانسان التاريخي العيني، الأمر الذي أدى بدوره الى تجاوز الطابع التجريدي المفارق

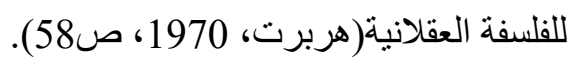

\section{المصادر والمراجع العربية والمُعربةبة}

- ابر اهيم، زكريا: هيجل او المثالية المطلقة، ضمن سلسلة عبقريات فلسفية، مكتبة مصر ، (ب. ط)، القاهرة، (ب. ت). - امام، عبدالفتاح امام: المنهج الجدلي عند هيجل، دار المعارف، ط2، القاهرة، (ب. ت).

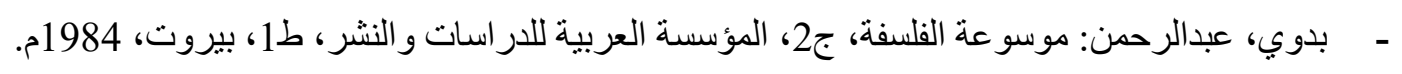
- حنفي، حسن: تطور الفكر الديني الغربي (في الأسس و التطبيقات)، دار الهادي للطباعة والنشر و التوزيع، ط1، بيروت،

2004

$$
\text { سيررو، رينيه: هيغل و الهيغلية، تر: نهاد رضا، دار الانوار، (ب. ط)، بيروت، (ب. ت). }
$$

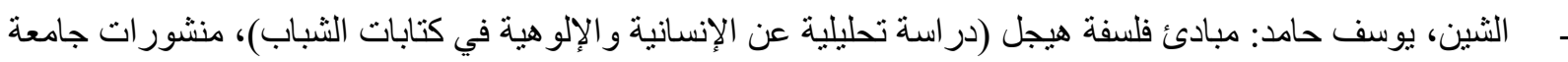
قازيونس، ط1، بنغازي، 1994م. غالي، و ائل: نهاية الفلسفة (در اسة في فكر هيجل)، مطابع الهيئة المصرية العامة للكتاب، (ب. ط)، (ب. م)، 2002م. كانط، ايمانويل: الدين في حدود مجرد العقل، تر : فتحي المسكيني، جداول للنشر والتوزيع، ط1، بيروت، 2012م. - كرونر، ريتشارد وكوبلستون، فردريك وسولمون، روبرت: تطور هيجل الروحي، ترجمة وتقديم وتعليق: إمام

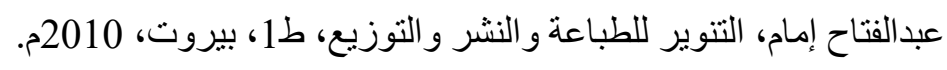

- كوبلستون، فردريك: تاريخ الفلسفة، مج7 (من فنته إلى نيتشه)، نر: إمام عبدالفتاح إمام ومحمود السيد أحمد، مر اجعة وتقديم: إمام عبدالفتاح إمام، المركز القومي للترجمة، ط1، القاهرة، 2016م. - كولينز، جيمس: الله في الفلسفة الحديثة، تر : فؤاد كامل، آفاق للنشر والتوزيع، ط1، القاهرة، 2019م. 
- - ماركيوز، هربرت: العقل و الثورة (هيجل ونشأة النظرية الاجتماعية)، نر: فؤاد زكريا، الهيئة المصرية العامة للتأليف

$$
\begin{aligned}
& \text { و النشر، (ب. ط)، (ب. م)، 1970م. } \\
& \text { - هيخل: المختار ات، ج1، تر : إلياس مرقص، دار الطليعة للطباعة و النشر، ط1، بيروت، 1978م. } \\
& \text { - - هيغل: حياة يسوع، نر: جرجي يعقوب، إثراف: إمام عبدالفتاح إمام، دار التنوير، ط3، بيروت، 2007م. }
\end{aligned}
$$

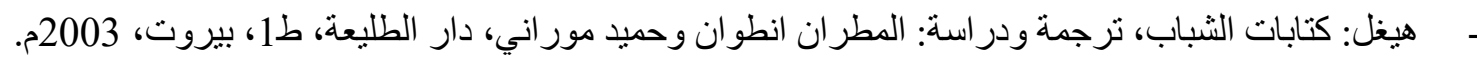

$$
\begin{aligned}
& \text { - - يسر، ميثم محمد: فلسفة الدين عند هيجل، ضمن كتاب فلسفة الدين (مقول المقس بين الايديولوجيا واليوتوبيا وسؤال } \\
& \text { التعددية)، مجموعة مؤلفين، اشراف وتحرير : علي عبود المحمداوي، منشورات ضفاف والاختلاف والأمان، ط1، } \\
& \text { بيروت و الجز ائر و الرباط، 2012م. }
\end{aligned}
$$

\section{Referenc:}

Ibrahim, Zakaria: Hegel or the absolute idealism, in the series of Philosophical Genius, Egypt .(Library, (BT), Cairo, (BT

Imam, Abdel Fattah Imam: The Dialectical Method of Hegel, Dar Al Ma'arif, 2nd Floor, Cairo, -

Badawi, Abdul-Rahman: Encyclopedia of Philosophy, Part 2, The Arab Foundation for Studies .and Publishing, 1st Edition, Beirut, 1984 AD

Hanafi, Hassan: The Evolution of Western Religious Thought (in Foundations and Applications), .Dar Al-Hadi for Printing, Publishing and Distribution, 1st Edition, Beirut, 2004 AD .(Sirro, Rene: Hegel and Hegelia, TR: Nihad Reda, Dar Al-Anwar, (B.I), Beirut, (B.T El-Sinn, Yusef Hamed: Principles of Hegel's Philosophy (An Analytical Study of Humanism and Divinity in the Writings of Youth), Gaziantes University Press, 1st Edition, Benghazi, 1994

- Ghali, Wael: The End of Philosophy (A Study in Hegel's Thought), Egyptian General Book Authority Press, (B. i), (B. M.), 2002 A.D.

Kant, Emmanuel: Religion is within the limits of mere reason, see: Fathi Al-Maskini, Tables for .publication and distribution, 1st Edition, Beirut, 2012

Kroner, Richard and Cobblestone, Frederick and Solomon, Robert: Hegel's Spiritual Evolution, translation, presentation and commentary: Imam Abdelfattah Imam, Al-Tanweer for printing, .publishing and distribution, 1st edition, Beirut, 2010 


\section{مجلة لارك للفلسفة و الذساذيات و العلوم الاجتماعية المجلد (2) العدد (41) السدة (2021) بحوث الفلسفة}

Cobblestone, Frederick: History of Philosophy, vol.7 (From his fascination to Nietzsche), see: Imam Abd al-Fattah Imam and Mahmoud al-Sayyid Ahmad, reviewed and presented by: Imam .Abd al-Fattah Imam, National Center for Translation, 1st Edition, Cairo, 2016

Collins, James: God in Modern Philosophy, TR: Fouad Kamel, Afaq for Publishing and .Distribution, 1st Edition, Cairo, 2019 AD

Marcuse, Herbert: Reason and Revolution (Hegel and the emergence of social theory), TR: Fouad Zakaria, The Egyptian General Authority for Authorship and Publishing, (B. i), (B. M.), 1970 AD. Heigl: Selections, Part 1, Tr: Elias Morcos, Dar Al-Taleea for Printing and Publishing, 1st .Edition, Beirut, 1978

Hegel: The Life of Jesus, Tr: Gerji Yaqoub, Supervised by: Imam Abdel Fattah Imam, Dar Al- .Tanweer, 3rd Edition, Beirut, 2007 AD Heigl: Young People's Writings, Translation and Study: Bishop Antoine and Hamid Morani, Dar .Al Taleea, 1st Edition, Beirut, 2003 AD

- Yusr, Maytham Muhammad: Philosophy of Religion for Hegel, within the book Philosophy of Religion (The saying of the sacred between ideology, utopia and the question of pluralism), a group of authors, supervised and edited by: Ali Abboud Al-Muhammadawi, Manhatat Dafaf, Difference and Safety, 1st ed. 